\title{
Fundamento ético de la cooperación internacional como política pública mundial
}

\section{Ethical Basis of International Cooperation as a Global Public Policy}

\author{
Jairo Agudelo Taborda ${ }^{1}$ \\ Universidad del Norte (Colombia) \\ ORCID: https://orcid.org/0000-0002-0396-6666
}

Recibido: 26-05-2020

Aceptado: 12-07-2021

\section{Resumen}

Este artículo es fruto de una investigación sobre Políticas Públicas Mundiales (PPM). En él se propone un fundamento ético de la cooperación internacional (CI) como PPM capaz de proveer los bienes públicos mundiales (BPM) del Sistema internacional (SI). Mediante un análisis del reciente marco teórico de la CI (institucionalismo, constructivismo, criticismo y cosmopolitismo) se sostiene que tales teorías, incluso aquellas basadas en la premisa hobbesiana de la natural anarquía y guerra de las sociedades, se inspiran en la ética cosmopolita kantiana. El artículo plantea, además, la urgencia de un sistema de gobernanza internacional dotado de una PPM centrada en la cooperación y capaz de proveer el supremo BPM: la paz con seguridad humana.

Palabras-clave: Ética cosmopolita, cooperación internacional, política pública mundial, bienes públicos mundiales, gobernanza mundial y paz.

\section{Abstract}

This article is a product of research about global public policies (GPP). In this is proposes an ethical basis of international cooperation (IC) as a

\footnotetext{
${ }^{1}$ (tabordaj@uninorte.edu.co). Profesor de Relaciones Internacionales en la Universidad del Norte. Doctor en Filosofía en la Universidad Lateranense de Roma y Doctor en Política Internacional de la Universidad Roma1 "La Sapienza". Autor de varios artículos, capítulos y libros sobre la cooperación internacional.
} 
GPP capable of providing public world goods (PWG) of the international system (IS). Through an analysis of the recent theoretical framework of IC (institutionalism, Constructivism, criticism and cosmopolitism) it is concluded that such theories, even those that do not declare it explicitly, are based on Kantian cosmopolitan ethics. Even those theories that are based on the hobbesian premise of natural anarchy in state of war. In this article also is suggests the urgency of an international governance system with a GPP focused in cooperation and capable to providing the world's supreme public good: The peace with human security.

Keywords: Cosmopolitan ethic, international cooperation, global public policy, public world goods and peace.

\section{Introducción}

Éste es un artículo de análisis teórico. Su método es de tipo cualitativo y explora el fundamento ético y epistemológico de la cooperación internacional (CI) en las principales Teorías de las Relaciones internacionales para identificar su principio fundante. Toma el actual marco teórico de la CI: Institucionalismo (Keohane), Críticismo (Habermas), Constructivismo (Wendt) y Cosmopolitismo (Held); lo analiza y concluye fundamentándolo en la ética cosmopolita kantiana.

La hipótesis sostenida es que la CI no es sólo un instrumento económico y político, sino que, sobre todo, se funda en un marco ético y axiológico como medio para un fin superior. La CI no es un fin sino un medio con función teleológica. El marco ético de la CI se basa en el cosmopolitismo de Immanuel Kant que se manifiesta en la teoría liberal de las Relaciones internacionales de Zimmern y Wilson, luego en el neoliberalismo institucional de Keohane y, hoy, en el cosmopolitismo de Held.

El análisis inicia conceptualizando la política pública nacional e internacional preguntándose si es científicamente oportuno hablar de Políticas Públicas Mundiales (PPM) y de Bienes Públicos Mundiales (BPM), como la paz y el desarrollo sostenible, en ausencia de un Gobierno mundial. El razonamiento lógico consiste en que, aún si se parte de la premisa hobbesiana de la natural anarquía y discordia competitiva de las sociedades primigenias, los humanos se asocian para buscar precisamente lo que la naturaleza no da: paz y seguridad. Lo real existente (discordia) genera lo ideal deseable (cooperación) como medio para lograr valores supremos (paz y seguridad) mediante instituciones (gobierno). Esto se ha dado en la historia a nivel local, nacional y mundial. Aquí se concluye que la mayor expresión del pensamiento ético mundial es el idealismo kantiano que, paradójicamente, termina siendo más 
realista que el realismo como lo demuestran las Organizaciones internacionales de cooperación que se inspiran en él como la Onu, la Oea, la Ue y otras.

El artículo asume que la CI como instrumento de las relaciones internacionales surge en las Organizaciones internacionales y en los regímenes internacionales conceptualizados por Krasner (1985) y Keohane (1989) como "consensos, normas y procedimientos aceptados voluntariamente por los actores del sistema internacional...". Luego, la CI se declina en términos de CI para el desarrollo (CID) deviniendo en la práctica aplicada funcional a la finalidad del desarrollo humano sostenible. Es tal nexo de regímenes internacionales, CI y CID que permite la identificación de un fundamento ético de la CI según sus principios y sus fines.

El texto, además, pretende superar la tradicional visión de la CI fundada en una ética altruista de solidaridad filantrópica de confesión religiosa o partidista. La CI se funda en una ética laica de mutuas conveniencias tal como lo propone Kant y los otros autores en sus obras aquí usadas y citadas como fuentes.

De una ética idealista kantiana de la política internacional (1795) que sustenta la teoría liberal de las relaciones internacionales, se infiere una ética realista de egoísmo iluminado de la CI en Keohane en su institucionalismo neoliberal para llegar a una ética de justicia internacional en Held expresada hoy en la cooperación internacional para el desarrollo devenida PPM para el supremo BPM: la paz mundial.

\section{Contextualización}

La Cooperación internacional (CI) cumple setenta y cinco años desde su adopción como subsistema de las relaciones internacionales en 1945 enmarcada en la Carta de San Francisco (Carta ONU, art. 1). En el Tratado constitutivo de la ONU, la CI se adoptó como una estrategia para lograr fines deseables y necesarios (la paz y la seguridad mundial), según sus Artículos 1, 55 y 56.

Un atento estudio de la evolución de la organización mundial nos lleva a los distintos proyectos de paz que florecieron en el S. XVIII, pero, sobre todo, al Proyecto para la paz perpetua de Immanuel Kant (1795). Tanto la Santa Alianza (1815) como la Sociedad de Naciones (1919) fueron intentos muy limitados de creación de un orden mundial como respuesta a la anarquía global. Sólo después de la Segunda Guerra Mundial se logra una jerarquía mundial duradera y sostenida inspirada en los tres artículos definitivos del proyecto de paz de Emmanuel Kant: republicanismo, federación de Estados libres y ciudadanía cosmopolita. (Kant, 2012).

El concepto kantiano de Federación de Estados libres y republicanos ha inspirado a la Sociedad de Naciones y a la Organización de Naciones Unidas 
a nivel global. Sucesivamente, estas Organizaciones universales inspiraron las Federaciones de Estados libres (y democráticos) a nivel continental y regional (Oea, Ue, Lpa, Ua, Asean, etc.). Más recientemente se han venido creando asociaciones subregionales de Estados más o menos democráticos (Celac, Aec, Unasur, etc.). Todas ellas basadas en la cooperación.

La evolución de CI en las teorías de las Relaciones internacionales (RI) coincide con el surgimiento de esta ciencia, en el 1919, con la teoría liberal elaborada sobre la premisa rousseauniana de la armonía natural de los intereses de los Estados aplicada al primer postconflicto Mundial. En la concepción liberal, la armonía estatal natural se rompe con un accidente en las relaciones entre los Estados (guerra) y se restaura mediante la cooperación entre Estados que crean normas e instituciones nacionales y supranacionales como la Sociedad de Naciones. Aunque la primera teoría de las relaciones internacionales que confrontó a la teoría liberal fue la del internacionalismo marxista de Lenin en el mismo período; la mayor antítesis de la teoría liberal vendrá a ser, durante y después de la Segunda Guerra Mundial, la teoría realista construida sobre la premisa hobbesiana de la conflictividad natural de los intereses de los Estados en condición anárquica. Para el realismo la guerra es un fenómeno natural debido a la original anarquía en la que surgen y actúan los Estados nacionales con soberanía absoluta patentada por el Tratado de Westfalia en 1648. En tal escenario lo habitual es la competición salvaje y no hay espacio para la cooperación (Morgenthau, 1986). De lo anterior se deduce que lo natural no es la cooperación sino la discordia y la competición. Entonces, no hay ni ha habido, ni habrá alguna armonía natural por recomponer mediante la hipotética cooperación como, en cambio, afirma la teoría liberal. Por tanto, la paz se impone mediante un equilibrio de poder.

\section{Marco teórico de la CI: la cooperación en la Ciencia de las Relaciones internacionales (RI)}

Después del Realismo de Morgenthau, el Neorrealismo (realismo estructural) de Kenneth Waltz (1979) considera que, a partir de la Conferencia de Yalta, en virtud de una progresiva reducción de la anarquía entre los actores de la escena internacional y de su consecuente articulación y estructuración en un sistema; los actores, descubren la posible conveniencia ocasional de cooperar más que de competir salvajemente. Esta teoría plantea una transición desde la imposibilidad de cooperar (Realismo clásico) hacia la probabilidad de hacerlo (Realismo estructural o Neorrealismo). Los actores naturalmente egoístas podrían cooperar cuando hacerlo facilite el logro de sus intereses. Tal enfoque está sustentado por el dilema del prisionero y la teoría de los juegos 
que admiten la posibilidad de que jugadores egoístas no sólo jueguen juegos a suma cero (con ganadores y perdedores. Gano yo si pierdes tú) sino también juegos a suma positiva más cooperativos que competitivos en los que hay solo ganadores (gano yo y ganas tú). El estudio de la cooperación en las teorías de las relaciones continúa su evolución lógica y cronológica con el institucionalismo neoliberal de Robert Keohane, Joseph Nye y Robert Axelrod en la década de los años 1980. En virtud de la multiplicidad de canales adquirida por las relaciones internacionales (multilateralismo) y de la diversificación de temas de la agenda internacional que supera la clásica obsesión de cada Estado por el dilema de la seguridad, los actores relativizan voluntariamente sus soberanías nacionales absolutas creando instituciones y generando redes de interdependencia que hacen más frecuente la propensión a jugar juegos a suma variable. Además, la intensificación de la frecuencia de los juegos aumenta la información entre los jugadores que permite intuir si los jugadores tienen la intención de cooperar o sólo de competir. En esta teoría se cristaliza la transición de los actores internacionales desde la posibilidad de cooperar (Neorrealismo) hacia la necesidad de hacerlo (Institucionalismo Neoliberal). La cooperación ya no es sólo posible sino necesaria para la obtención eficaz y eficiente de los intereses propios. Así las cosas, la cooperación internacional no es fruto de la armonía entre los Estados sino de su natural discordia (Keohane, 1984). Si hubiese armonía no se necesitaría la cooperación que se tipifica, precisamente, como la armonización de políticas entre actores egoístas para maximizar y optimizar el logro de sus propios intereses (Keohane, 1984). O sea, que la cooperación internacional surge como una estrategia entre egoístas y no entre altruistas.

Esta es la esencia de la concepción de la cooperación internacional como self-help o auto-ayuda. Este concepto es importante porque despeja el terreno de posibles interferencias moralizantes o confesionales en el análisis político del tema y lo coloca en la esfera de una ética humana natural.

El pretendido altruismo de la cooperación es, probablemente, una fase más elaborada, que califica y adjetiva a la cooperación, pero que no la sustantiva. Es más, se podría decir que la misma cooperación altruista y solidaria es sostenible en la medida en que los cooperantes perciben sus objetivos como intereses primariamente propios y secundariamente comunes. Aquí radica la probabilidad de convertir la cooperación internacional en política pública mundial precisamente por su esencial y original carácter egoísta en torno a intereses propios y/o comunes, en sentido laico y no confesional. Así como relativizar la soberanía nacional de un Estado para entrar a ser parte de instituciones multilaterales y/o regímenes internacionales (Krasner, 1983), no implica renunciar a la soberanía nacional sino adoptar otro modo de soberanía, así mismo, cooperar para obtener intereses propios que se vuelven comunes, no significa que esos mismos intereses dejen de ser individuales y 
particulares (egoístas). Es otro modo de obtener sus propios intereses respecto a la mera competición en la escena internacional. En la interdependencia de las relaciones internacionales los jugadores juegan a ganancias asimétricas, pero sin perdedores, lo cual les permite seguir jugando y haciendo que la puesta en juego sea cada vez mayor y más compleja. Tal margen de ganancia, mínima o máxima que sea, genera incentivos para la propensión a los juegos a suma variable.

De este modo el sistema internacional completa su ciclo transformador. De ser puramente competitivo pasa a ser competitivo-cooperativo y de éste a otro cooperativo-competitivo predominante en la era de la interdependencia compleja. La interdependencia y la cooperación tipifican una ecuación directamente proporcional: a más cooperación mayor interdependencia y viceversa.

\section{Los bienes públicos mundiales, BPM}

Desde el punto de vista económico, la teoría de los Bienes Públicos Mundiales (BPM) deriva de la teoría de los Bienes Públicos Nacionales (BPN) tratada desde los clásicos como Smith (1776), luego Samuelson (1954) y ahora Krugman (2012) y Stigliz (2015). El concepto de Bien Público (BP) adquiere connotaciones respecto al Bien Privado. Tales connotaciones son: la no rivalidad y la no exclusividad en su consumo (Agudelo, Miranda y Toro. 2010, 35-40).

Según la no rivalidad, la ampliación del número de consumidores de un bien no reduce los beneficios de su consumo para la totalidad de sus consumidores. En virtud de la no exclusividad, una vez provisto el bien, no es posible excluir de su consumo a ningún potencial consumidor como lo expresan Kaul, Grunberg y Stern (2001) en su obra Bienes públicos mundiales: la cooperación internacional en el Siglo XXI, referente esencial para este artículo: Los bienes públicos se reconocen por tener beneficios que no se pueden limitar con facilidad a un solo "comprador" (o conjunto de "compradores"). Sin embargo, una vez que se proporcionan, muchos pueden disfrutar de ellos gratuitamente... ejemplo, un medioambiente limpio.

Ahora bien, los individuos, los grupos y las sociedades necesitan y demandan bienes privados y bienes públicos. La diferencia entre bienes públicos y privados se conoce técnicamente como externalidad que puede ser negativa o positiva. La educación, por ejemplo, es un bien público con múltiples externalidades positivas. El problema es que estos bienes se proveen, casi siempre, en cantidades insuficientes respecto a sus demandantes. 
Habitualmente se piensa que el bien privado pertenece a la jurisdicción del Mercado y que el bien público es competencia exclusiva del Estado. Esto induce a pensar que para que haya un bien público, se necesita un Estado que lo provea y lo tutele. Aunque desde el punto de vista operativo esto sea cierto, hay que recordar que no es el Estado el que genera los bienes públicos, sino que es la concepción difundida en la sociedad de la existencia de un bien público la que genera al Estado (o institución) capaz de proveerlo y tutelarlo. Tanto en el paradigma rousseauniano como en el hobbesiano, los individuos en la sociedad primigenia crean el artificio llamado Estado cuando conciben la convivencia social como un bien público tan importante para su propia supervivencia que vale la pena relativizar su amada libertad natural y absoluta para ganar en términos de seguridad (Agudelo, Miranda y Toro. 2010, 35-40).

Desde las décadas de los años ochenta y noventa del siglo XX, con la elaboración de los conceptos de desarrollo humano (Sen, 1981) y de seguridad humana (Buzan, 1983) y su posterior adopción de ambos conceptos por parte del Programa de las Naciones Unidas para el Desarrollo (PNUD) como objetivos hacia los cuales dirigir la cooperación internacional, se han identificado en torno a tal objetivo algunos bienes públicos considerados de interés mundial. Ellos son, entre otros: democracia, derechos humanos, justicia mundial, ambiente sano, estabilidad financiera, seguridad alimentaria, paz y seguridad.

De manera que los BPM son aquellos beneficios no excluibles, sin rivales, que atraviesan fronteras, poblaciones y generaciones. Es así que los beneficios de un BPM se extienden a grupos de países sin discriminación de grupos poblacionales presentes o venideros (Kaul, Grunberg y Stern, 2001). Se infiere, entonces, que probablemente los BPM inician siendo nacionales, pasan a ser regionales para terminar siendo mundiales.

Pero ¿cuándo y cómo se mundializaron algunos bienes públicos nacionales? Este proceso no es tan nuevo como se cree. Probablemente se remonta al siglo XVII cuando Hugo Grozio concibió el mare liberum como un bien común universal. Se consolida en el siglo XIX con las llamadas reglas internacionales del tráfico y con las organizaciones internacionales que reglamentaban los servicios postales y las comunicaciones. Se trata, entonces, de bienes y servicios nacionales que se han regionalizado y mundializado.

La explicación de este proceso mediante el cual algunos bienes públicos nacionales se mundializan la podemos encontrar en el enfoque sistémico de la política internacional (Waltz, 1979), según el cual, si bien son las unidades autónomas las que crean el sistema internacional, éste, al consolidarse, pasa a determinar el comportamiento de las unidades autónomas tanto en sus relaciones horizontales (entre las unidades autónomas) como en las verticales (las unidades hacia el sistema y viceversa). El condicionamiento del sistema sobre las unidades autónomas es cada vez mayor respecto al condicionamiento 
de éstas entre sí y de ellas hacia el sistema. Este fenómeno se ha hecho más evidente en materias sensibles como los derechos humanos y el cambio climático.

Pero la historia ha enseñado que los bienes públicos son deseables exactamente porque no se poseen. Lo que se tiene en modo tangible y real son los males públicos. Así que el bien público se percibe como antídoto a un mal público. Esto vale tanto para la escala nacional como para la internacional. En ello radica el constante riesgo reduccionista de las agendas tanto nacionales como internacionales que generalmente se limitan a paliar y mitigar males sin por ello necesariamente generar bienes. Aunque también la reducción del daño comporte acciones de políticas públicas como por ejemplo la mitigación de los efectos del cambio climático, estas son políticas necesarias pero insuficientes para proveer bienes públicos nacionales, regionales y mundiales como la sostenibilidad ecológica. De hecho, son políticas paliativas o de mitigación de los males, pero para nada resolutivas de ellos y, por lo tanto, no generadores de verdaderos bienes.

De la misma manera, se llegó a percibir la paz como un bien público cuando se percibió la guerra como un mal público, como un juego a suma menor que cero con sólo perdedores. Son los efectos sistémicos de los males públicos los que hacen deseables los bienes públicos mundiales. Sólo cuando se difundió una concepción de la guerra como mal público mundial, se pasó a concebir la paz y la seguridad como BPM y, consecuentemente, se inició el proceso de construcción de algo parecido a un Gobierno mundial para mitigar ese mal público mundial llamado guerra y/o proveer el BPM llamado paz y seguridad internacional. Así que la conciencia más o menos difundida de un BPM antecede a la existencia del Estado Global que lo provea y tutele, entendido como gobierno central. Y la percepción de un mal público mundial (MPM) antecede la concepción de un BPM que lo combata. La historia enseña que los horrores de la Primera Guerra Mundial (MPM) generaron y difundieron la percepción de la paz y de la seguridad como un bien público que superaba las fronteras de los Estados, y que sólo en cuanto transnacional, mediante los principios de no rivalidad y no excluibilidad, puede realizarse plenamente como BPM. Sólo cuando la guerra se mundializó (Primera Guerra Mundial), se intentó mundializar la paz con Zimmern, Wilson y Lenin. Frente a un Mal Público Mundial (guerra) hay que oponer su antídoto como BPM (paz). El proceso inicia con un pacto negativo (de no agresión) esperando pasar luego a un pacto positivo (de cooperación), según Bobbio (2008). Desde el punto de vista filosófico, la teoría de los BPM deriva del cosmopolitismo kantiano (Kant, 1795), declinado luego en la ya citada tradición liberal de las Relaciones Internacionales de Alfred Zimmern y Woodrow Wilson en 1919. Se recuerda aquí que, a pesar de su idealismo filosófico, Kant es realista cuando dice que la 
naturaleza no nos dio en herencia la paz sino la guerra. Posteriormente, en el campo de los estudios internacionalistas, se relaciona la teoría de los BPM con la doctrina de los regímenes internacionales (Ruggie, 1975 y Krasner, 1983) y de la interdependencia compleja (Keohane, 1988). Como ya se dijo, la teoría de los BPM toma forma en los estudios de Kaul Inge, Isabelle Grunberg y Marc Stern (Inge, Grunberg y Stern, 2000), desde el seno de la ONU (PNUD). En estos documentos se usa la expresión Bienes Públicos Globales (BPG) que aquí prefiero llamar Mundiales, BPM, para no incurrir en equívoco con los defensores de la actual globalización.

Pero, ¿es posible hablar de BPM en ausencia de un Gobierno Mundial que los provea? En caso afirmativo, ¿qué pasa con la soberanía de los Estados nacionales? Y, ¿cuáles serían esos BPM? Con Keohane y Krasner se puede responder a la primera cuestión afirmando que hay un proceso de interdependencia compleja mediante instituciones mundiales y regímenes internacionales que tienen como mandato sectorizado proveer, reglamentar y tutelar un bien público global específico. Algunas de tales instituciones están articuladas a la ONU, como sus institutos especializados y sus agencias. Otras son externas a la ONU como la Organización Mundial del Comercio (OMC).

Respecto a la segunda cuestión, tal proceso constructivo de instituciones internacionales no contradice la soberanía de los Estados nacionales, ya que los órganos multilaterales se crean por soberana y libre voluntad de los Estados que firman y luego, mediante procedimiento constitucional, ratifican su adhesión. No es una pérdida de soberanía, sino una forma distinta ejercerla sobre algunos bienes que superan el interés nacional. De un ejercicio singular de soberanía absoluta de cada Estado, se pasa a una especie de soberanía colectiva sobre determinados tópicos aceptados como de interés transnacional. Sólo de este modo se entienden algunos conceptos que son ya patrimonio mundial, como crimen de lesa humanidad, deber de proteger, patrimonio de la humanidad. Ya se conciben males que no lesionan sólo una determinada población en razón de su nacionalidad, sino que lesionan una identidad cosmopolita y humana (Held, 2012). Por tanto, el recurso para evitar cualquier mal de la humanidad se tipifica como un BPM que pertenece a la soberanía de los Estados tanto individual (nacional) como colectivamente (internacional) considerados. Para resolver la pregunta sobre cuáles son hoy los BPM, se puede afirmar que, históricamente, el primer BPM concebido como tal fue el de la seguridad de los Estados. El viejo dilema de la seguridad, que connotaba un escenario anárquico dependiente sólo de la capacidad de autodefensa de cada Estado en condiciones naturalmente hostiles y conflictivas, produjo las guerras y, sobre todo, las dos grandes guerras mundiales del siglo XX con la exacerbación de los nacionalismos. En época bipolar, tal dilema produjo una nueva generación de guerras en las dos áreas de influencia en que se dividió el globo. Proliferaron guerras internas y/o civiles 
(ej: Colombia). Entonces, como ya se dijo, un mal mundial real llamado guerra, generó la concepción de un bien mundial deseable llamado paz y seguridad. De allí surge la necesidad de instituciones que provean o tutelen este BPM: desde la Sociedad de Naciones en 1919, luego la Organización de Naciones Unidas en 1945 y, más recientes, las Organizaciones multilaterales regionales como la Unión Europea, la Organización de Estados Americanos, la Unión Africana, la Liga de países árabes, la ASEAN y otras.

Por lo tanto, en el proceso constructivo de regímenes internacionales, este adjetivo (internacional) tiene un peso político específico sustantivo. Ese proceso nace siendo interestatal, pero su predicción es que llegue a ser internacional, es decir, entre naciones, entre pueblos, reconociendo un rol determinante de las sociedades civiles de tales Estados, conforme a los contenidos en el preámbulo de la Carta de la ONU: "Nosotros los pueblos de las Naciones Unidas resueltos a preservar a las generaciones venideras del flagelo de la guerra que dos veces durante nuestra vida han infligido a la humanidad sufrimientos indecibles [...]" (Carta ONU, 1945). De hecho y de derecho, son las sociedades civiles las que conciben los BPM y las que, mediante sus demandas (Easton, 2006), definen el tipo de Estado idóneo para proveerlos y tutelarlos. Se puede afirmar entonces que, para llegar a un Gobierno mundial, se requiere una sociedad civil mundial que lo genere por analogía doméstica; es decir, que la calidad de los Estados (y sus gobiernos) elegidos por las sociedades civiles (se espera), tributará a favor de la calidad del sistema internacional. Las sociedades civiles convergerán en una sociedad civil mundial que demandará un sistema global. El Pacto Global expresado en la Carta de la ONU, confirma la concepción de la seguridad como BPM prioritario y fin constitutivo de la naciente institución. Pero la Carta de la ONU va más allá: asocia a este BPM otros dos sin los cuales la seguridad y la paz no son realizables. El primero, promover mejores condiciones de vida para todas las personas del planeta; y el segundo, garantizar los derechos humanos fundamentales universales sin distinción alguna. Se puede asumir entonces que, lo que hoy se conoce como derechos humanos y el desarrollo humano, son concebidos en la Carta de la ONU como BPM (ONU, 1945, Art. 1). Ahora bien, la Carta de la ONU es un tratado internacional de obligatorio cumplimiento para los Estados que soberanamente la han ratificado. Los Estados que forman parte de este pacto, suman hoy 193. En torno a estos BPM se crea un nuevo sistema mundial con un marco político multilateral y el marco jurídico del derecho internacional que encuentra su mayor aplicación en el campo de los derechos humanos. A este Pacto Global se suman los recientes pactos globales aún no jurídicamente vinculantes pero ética y políticamente convenientes, entre los que se encuentra la reciente Declaración del Milenio que adopta como BPM los ocho Objetivos de Desarrollo del Milenio (ODM) y luego los 17 Objetivos de Desarrollo Sostenible (ODS), dentro de los cuales está el derecho al ambiente 
sano. No hay duda de que los efectos del calentamiento global, percibido como un mal global, suscitan la mayor convergencia en torno al ambiente sano como BPM. Hay ya un consenso consolidado en torno a los siguientes BPM: La seguridad humana y la paz; los derechos humanos fundamentales; el desarrollo humano sostenible; el ambiente sano; La estabilidad financiera; la democracia (Agudelo, Miranda y Toro, 2010). Por oposición, la ausencia de tales BPM es percibida como presencia de Males Públicos Mundiales (MPM) que el sistema internacional debe combatir. Así como en los sistemas nacionales, los bienes públicos se proveen o tutelan mediante políticas públicas nacionales, también los BPM se deben proveer o tutelar mediante políticas públicas mundiales.

Pero, ¿cómo emanar y adoptar PPM en ausencia de un Gobierno mundial? Es verdad que aún no existe un Gobierno mundial, pero sí un sistema mundial de regímenes internacionales con diferentes actores tal como ya se ha enunciado aquí con Ruggie, Krasner y Keohane. Sin embargo, la pregunta clave es sobre si ¿hay ya una sociedad civil mundial capaz de demandar políticas públicas mundiales, por analogía doméstica en la visión de Easton y Luhmann? No hay dudad de que hoy toda sociedad mínimamente ordenada está constituida por tres sectores: Estado, Mercado y Sociedad civil. ¿Esto es ya válido también para la sociedad internacional? Tal vez lo más científicamente exacto es afirmar que de los tres sectores, sólo el segundo (Mercado) se ha mundializado mediante la omnipresente globalización del comercio, la finanza y la economía. Los otros dos sectores están, cuanto más, en proceso de mundialización. Como ya se dijo, probablemente no habrá un estado mundial (primer sector) mientras no haya una sociedad civil mundial (tercer sector) sólida y demandante de instituciones y políticas mundiales como sucede en las democracias nacionales. Pero los BPM no deben ser proveídos exclusivamente por los Gobiernos de los Estados, sino por todos los actores del Sistema Mundial: Estados, Organizaciones multilaterales, Organizaciones de la sociedad civil, empresas multinacionales y nacionales (con Responsabilidad Social Empresarial) e Individuos. De nuevo, se trata de los tres sectores de la sociedad mundial: Estados, Mercado y sociedad civil. Naturalmente, la mayor onerosidad recae sobre los Estados, aunque de modo no exclusivo. De hecho, la Carta ONU propone, como política mundial para afrontar los males globales, "Realizar la cooperación internacional en la solución de problemas internacionales de carácter económico, social, cultural o humanitario [...]" (Carta ONU, 1945, Arts. 1-3). De ahí se deduce que la Cooperación Internacional está prescrita como política pública del sistema internacional en tanto proveedora de los BPM. Pero las políticas públicas requieren recursos técnicos, humanos y financieros. Pues bien, la cooperación internacional para el desarrollo (CID) se está dotando poco a poco de tales recursos. Por ejemplo, a partir de la Declaración del Milenio (ONU, 2000) y del Consenso de Monterrey (ONU, 2002), la Ayuda Oficial para el Desarrollo 
(AOD) ha aumentado considerablemente y su aplicación está orientada al logro de los ODS en el mundo, según la Agenda 2030. Así mismo, con la Declaración de París (2005), la Cooperación Internacional se dotó de mejores recursos técnicos y humanos para hacerla más eficaz y eficiente. A ello se agrega la adopción de este pacto por parte de la Sociedad Civil Mundial mediante la Agenda de Acción de Accra en 2008. En este artículo se afirma que la CID no es un BPM en sí, sino que está llamada a ser la PPM capaz de proveer y tutelar los BPM como el respeto universal a los derechos humanos y a las libertades fundamentales de todos. Así está concebida en el Artículo $55 \mathrm{y}$, sobre todo, en el Artículo 56 de la Carta de la ONU: Todos los miembros se comprometen a tomar medidas conjunta o separadamente, en cooperación con la organización, para la realización de los propósitos consignados en el Artículo 55. La primera subjetividad del deber de cooperar recae sobre el Estado, conjunta o separadamente. Además, este pacto global vincula jurídicamente a los 193 Estados miembros de la ONU por haber ratificado la Carta y a los Estados no miembros mediante el derecho internacional consuetudinario.

Es innegable, entonces, que la humanidad asiste a un avance de la interdependencia y de la transnacionalización de los problemas y de sus intentos de soluciones. En el caso de América Latina, se vive un renacido intento de integración en nuevos órganos multilaterales subregionales como la Unión de Naciones Suramericanas (UNASUR), y semi-continental, como la Comunidad de Estados Latinoamericanos y Caribeños (CELAC).Todo hace pensar en una renovada voluntad de interpretar el desarrollo humano, el ambiente sano, la estabilidad financiera, la democracia, los derechos humanos fundamentales y la seguridad (entre otros) como Bienes Públicos Regionales (BPR), cuya garantía depende de órganos multilaterales regionales y de la cooperación entre ellos de Sur a Sur (Ayllón, 2013).

\section{La Política pública mundial, PPM}

La definición de Política pública en lenguas neolatinas es compleja por la no distinción entre politics (pugna por el poder), polity (sociedad política) y policy (ejercicio del poder) que en cambio existe en las lenguas anglosajonas. Por tanto, adoptamos aquí la definición de Mény y Thoenig (1986) reportada por Roth (2004) según la cual la política pública es el programa de acción de las autoridades públicas en el seno de la sociedad. Se trata entonces del outcome en la caja negra del enfoque sistémico de Easton. O sea, un output dotado de plan de acción estratégico y de recursos suficientes para realizarlo eficaz y eficientemente (Easton, 2006). 
Se infiere así que para que exista una política pública mundial se requieren al menos dos condiciones: una autoridad mundial y una sociedad mundial. $\mathrm{O}$ sea, un sistema (sociedad política) distinto del ambiente sobre el cual y por el cual actúa (sociedad civil), en la visión sistémica de Easton a escala nacional y de Waltz a nivel internacional. No hay duda de que la interdependencia compleja ha reducido la anarquía y el absolutismo unilateral de las soberanías de los Estados. Sin embargo, como ya se ha dicho, no existe todavía un gobierno mundial central lo cual nos induciría a pensar que no puede existir ninguna política pública mundial faltando su principal actor generador y ejecutor. La cuestión no es tan simple pues si bien es cierta la ausencia de un gobierno mundial central, es también cierto que, como se ha dicho citando a Ruggie (1975), Krasner (1983) y Keohane (1984); existen los llamados regímenes internacionales como conjuntos de normas y prácticas consensuadas sobre sectores específicos de la sociedad mundial y que han sido adoptadas con carácter tanto política como jurídicamente vinculantes. Así mismo, existe, al menos desde el 1945 y probablemente antes, una especie de sociedad mundial constituida por una pluralidad de actores estatales y no estatales que demandan regímenes internacionales (Keohane) en sectores específicos mundiales como el comercio, la seguridad y la paz. De tal modo que podemos decir que, aun no existiendo un gobierno mundial central, existe un conjunto de ministerios con autoridad legítima para adoptar programas de acción (policys) y estrategias (outcomes) sobre sectores específicos (issues) capaz de proveer bienes públicos demandados por actores internacionales hacia el interior y hacia el exterior de sus fronteras. Además, tales acciones son demandadas por diferentes actores de la sociedad mundial estructurada, a su vez, en regímenes territoriales regionales (OEA) y sub-regionales (CELAC, UNASUR, CAN y otras).

Siguiendo a Mény y Thoenig (1986) en la definición de política pública, podemos inferir que una política pública mundial es el programa de acción de las autoridades públicas internacionales en el seno de la sociedad mundial.

\section{La cooperación internacional para el desarrollo: PPM para BPM}

Se ha definido la cooperación internacional, con Keohane, como la coordinación de políticas entre actores egoístas para maximizar y optimizar el logro de sus propios intereses. Se puede asumir que hoy la cooperación internacional es el conjunto de políticas coordinadas de los actores del sistema mundial para lograr intereses tanto propios (unilaterales) como comunes (multilaterales). Por lo tanto, la CI hoy se constituye como el programa de acción de las autoridades públicas internacionales en el seno de la sociedad mundial (Mény y Thoenig, 1986). 
La máxima expresión práctica de aplicación de la CI como intento de gobernanza mundial está representada hoy por la cooperación internacional para el desarrollo (CID). Es en este campo aplicativo (para el desarrollo) y en el de los derechos humanos (que en el concepto de desarrollo humano coinciden) donde más se han elaborado interdependencias, juegos a sumas positivas y regímenes internacionales. Es lo más cercano a una posible PPM. De hecho, este tipo específico de cooperación se ha dotado de un marco político y jurídico cada vez más complejo y de un fondo de recursos económicos más conspicuo. Tal complejidad es debida a la ampliación y la profundización que ha experimentado el concepto de desarrollo en cuanto objetivo de la CI. El concepto de desarrollo ha integrado variables y sectores nuevos en sus contenidos pasando de significar sólo crecimiento económico a contener otras variables sociales, éticas, culturales, políticas, jurídicas y ecológicas. Hoy el concepto de desarrollo humano contiene en sí a todos los derechos humanos fundamentales tanto civiles y políticos como económicos, sociales y culturales; al igual que los de reciente generación: derecho a la paz, derecho al ambiente sano y derecho al desarrollo humano mismo que podría incluir los anteriores.

Por ello, se puede afirmar que la CID es, hasta ahora, lo más cercano a una PPM para proveer el desarrollo humano sostenible como BPM. De hecho, la AOD ha superado los 140.000 millones de dólares en el 2017 (Informe CAD. 2018) y no propiamente en época de bonanza sino de crisis de los principales donantes del Comité de Ayuda al Desarrollo (CAD) de la Organización para la Cooperación y el Desarrollo Económico (OCDE). Sin embargo, Kaul y Blondin (2015), estudiando el problema de la provisión de BPM identifican tres grandes lagunas por colmar: laguna de jurisdicción; laguna de participación y laguna de incentivación. Esto vale también para la CID aunque a nivel atenuado.

Sobre la jurisdicción de la provisión de BPM, no hay duda que esta inicia a nivel nacional. Ello se debe a que no todas las naciones tienen la capacidad y/o la voluntad de adoptar políticas públicas nacionales que provean BPM. He ahí la laguna. Por tal razón, se propone la creación de un circuito jurisdiccional que vaya desde lo nacional a lo internacional y de regreso a lo nacional por medio de varios niveles intermedios, regionales y subregionales. Sin embargo, es necesario que estén integrados de un modo más sistémico, por el interés nacional de todos, así como por el interés supranacional, mundial (Kaul y Blondin, 2015).

Para ello, entre muchos pasos por cumplir, se requiere vincular las agendas de políticas nacionales y mundiales evidenciando los beneficios locales de la cooperación internacional. Es decir, las ventajas de cooperar entre las unidades autónomas y el sistema estructurado con retorno sobre las unidades mismas como incentivo inherente. Este proceso, además, fortalecería la cooperación regional como plano intermedio. Ello requiere un manejo sistémico de las 
cuestiones mundiales. Naturalmente, las externalidades positivas de los BPM alimentan el riesgo de los llamados free ryders tanto a nivel nacional como mundial. Por lo cual, el sistema debe generar su antídoto.

En relación con la laguna de participación en la provisión de BPM, tanto los teóricos del realismo estructural como los del institucionalismo neoliberal coinciden en identificar dos modalidades: hegemónica y democrática. En la primera es el Estado dominante el que se atribuye la erogación de BPM porque ello tributa a favor del mantenimiento del statu quo que le conviene. Tal modalidad se ha demostrado insostenible y ha terminado por convertir los BPM en indeseables y confundibles con males públicos mundiales debido a la proliferación de externalidades negativas generadas. En la modalidad democrática o participativa hay un empoderamiento efectivo de una pluralidad de actores de la escena internacional con capacidad de proveer los BPM. Por lo tanto, requiere una reducción de la dependencia del Sur del mundo respecto al Norte y de la periferia respecto al centro según la visión neo-marxista de Cardoso y Falleto (1977) y del sistema mundo de Wallerstein (2005). Requiere un esquema poliárquico. Por ejemplo, hoy el G20 representa una instancia potencialmente proveedora de BPM pero aún no efectiva. Todas las unidades del sistema, y el sistema mismo, deben corresponsabilizarse de tal provisión, estatales y no estatales.

Respecto a la laguna de incentivación, aunque la cooperación internacional sea un medio y no un fin, esta debe ser considerada como aportante de más beneficios netos que de costos aun para las unidades a escala nacional. Ahora bien, los incentivos no son sólo de tipo cuantitativo sino también cualitativo como el prestigio para algunos países y para algunos Organismos multilaterales como la Unión Europea. Para ello, también los incentivos deben ser estructurados y sistémicos. La provisión de bienes requiere una arquitectura financiera que la haga sostenible y una estructura de incentivos que la vuelva constante y progresivamente apetecible.

La CI no sólo puede, sino que debe, constituirse como la PPM proveedora de los BPM. La tesis aquí sostenida y, que pretende ir más allá de los autores Kaul y Blondin es que no existe aún una sociedad civil global cohesionada que demande contundentemente las PPM. La pregunta que surge espontánea es: ¿aún si existiera una sociedad civil mundial, a quién le demandaría tales PPM para BPM, en ausencia de un Gobierno central mundial? La respuesta sería: a los regímenes internacionales existentes como expresión de una especie de gobierno mundial descentralizado y poliárquico multinivel. Un gobierno mundial no entendido en oposición a los gobiernos nacionales sino fruto de la coordinación entre ellos a escala sub-regional, regional y universal. Para ello se da por sentada la existencia de un conjunto de BPM cuya tutela demanda PPM por parte del sistema mundial. El mejor avance en esta dirección lo representa 
la CID. Éste es el ámbito más cercano a forjar tanto un consenso como agenda mundial compatible con la soberanía estatal inteligente e interdependiente, tal como está sucediendo en torno a la seguridad colectiva y a la mundialización de respuestas colectivas al cambio climático y al terrorismo. Además, son objetivos previstos en la Agenda 2030 y sus ODS.

Así mismo, la teoría de las relaciones internacionales que más encarna el anhelo de una gobernanza mundial capaz de emanar PPM proveedoras de los ya existentes BPM, es la teoría cosmopolita en la versión reciente de David Held (2012) en la cual convergen elementos significativos del Institucionalismo neoliberal, las críticas del neo-marxismo de Wallerstein y la dimensión social del constructivismo de Wendt. La teoría cosmopolita de las relaciones internacionales recoge una tradición clásica que viene desde los estoicos griegos pasando por Kant, Kelsen, Rawls, Sen, Bobbio, Falk, Habermas, Beck, Bauman, Cassese, Archibugi y Sandel. Sus mayores críticos son, naturalmente, los realistas y un buen grupo de neo-marxistas que confunden los cosmopolitas con los apologistas de la actual globalización (Zolo, 1997). Sin embargo, los cosmopolitas no son globalistas. Todo lo contrario, critican mordazmente los límites, las escuelas y las secuelas de la actual globalización. Su origen y connotación teórica encarna el dilema ya existente desde la Grecia clásica entre la polis-local y la cosmopolis. Ya entonces se asumía la relación dialéctica entre la polis-local y la polisuniversal. La polis-universal constituye el sistema estructurado de las polis locales. Así la interpretan luego Kant en Para la paz perpetua (1795) y Kelsen en 1944 en La paz por medio del derecho. Tanto Kant como Kelsen afirman la doble ciudadanía de pertenencia: la ciudadanía entendida como nacionalidad (polislocal) y la ciudadanía cosmopolita (polis- universal) que no riñen entre ellas, sino que se realizan plenamente en virtud de su interacción a varios niveles (polis y cosmópolis). En ambos niveles el centro de la realización es el mismo ciudadano, sujeto de los mismos derechos y deberes. Agente y no paciente. Activo y no pasivo. Demandante, individual y colectivamente, de bienes públicos locales, sub-regionales, regionales y universales. La cosmo-politización es mucho más que la globalización pues reconoce la ciudadanía multinivel de su actor principal: el ser humano titular de derechos humanos fundamentales tanto individuales (derechos civiles y políticos) como colectivos (derechos económicos, sociales y culturales) ya codificados en los dos Pactos universales de derechos humanos en vigor desde el 1976. Pero el sistema político que mejor ha logrado tutelar tales derechos llamados hoy derechos de ciudadanía (en polis y en cosmópolis) ha sido, según Held y Sen, la democracia. Aquí se propone ir más lejos afirmando que el mejor sistema político hasta ahora conocido para tutelar los derechos humanos fundamentales, incluyendo el derecho al ambiente sano, de todas las generaciones ha sido el Estado Social de Derecho realizado, en su mejor expresión por la social-democracia que prioriza la búsqueda de la equidad. 
Pero la actual globalización no es la mundialización deseada capaz de promover justicia, equidad, democracia, estabilidad, seguridad y ecología a nivel mundial. El mundo está aún lejano de funcionar como si fuera un Estado Social de Derecho. Esto es debido a que no se ha mundializado la política declinada en términos de social-democracia. Es más, no se ha aún mundializado la simple democracia pues, según el informe de democracia en el mundo publicado cada año por la Revista The Economist, (Democracy Index 2019), en el 2018 sólo la mitad de los países del mundo vive en democracia liberal. Probablemente, sin una mundialización de la democracia (social) no se llegará a una poliarquía universal y mucho menos a un Estado de bienestar mundial (Luhmann, 2007). Para ello, además de la globalización del mercado (ya lograda) se tiene que mundializar la política (Estado) y, sobre todo, la sociedad civil (Kaldor, 2005). Probablemente cuando exista una sociedad civil mundial, ésta demandará un nivel de gobernanza mundial capaz de adoptar la cooperación como política pública mundial que regule el mercado global en clave keynesiana. Se requiere una transición hacia el multilateralismo multipolar proyectado por las teorías institucionalistas, cosmopolitas y constructivistas de las relaciones internacionales. Además de una laguna jurisdiccional en la gobernanza mundial hay que subsanar con urgencia una laguna jurídica mediante un Tratado internacional sobre la cooperación como política pública mundial. Seguramente, la actual globalización es un bien necesario pero insuficiente en cuanto parcial y reductiva. De los tres sectores de la sociedad internacional, sólo se ha globalizado plenamente el mercado (segundo sector), ni la sociedad civil mundial (tercer sector), ni el Estado mundial (primer sector) existen aún. Urge entonces una mundialización mundial que no es un juego de palabras sino un juego a suma mayor que cero. Una mundialización entendida como cosmo-politización (Held, 2012) y no como globalización.

Así como un Estado Social de Derecho a escala nacional está determinado por los tres sectores equilibrados que se intersectan: Estado, Mercado y Sociedad civil; así mismo, por analogía doméstica, es deseable a escala internacional. Tal vez a nivel regional, lo más semejante a este proceso es el de la Unión Europea (UE) a pesar de su actual crisis ya decenal. No es casualidad que Europa haya sido la región inventora del Estado de bienestar y mayor promotora de la CI llegando a aportar cerca del $60 \%$ del total de la AOD equivalente a cerca de 80 mil millones de dólares de los 140 mil millones de la totalidad de la ayuda pública para el desarrollo. (Informe CAD-OCDE, 2018).

En extrema síntesis, basado en la teoría cosmopolita heldiana, este capítulo se adhiere al diagnóstico de déficit de gobernanza mundial por falta de capacidades y responsabilidades convergentes a nivel supranacional. Esto se evidencia, sobre todo, en la incapacidad e irresponsabilidad de gobernar los actuales males mundiales como el cambio climático, la crisis financiera, la inseguridad (Held, 2012). La propuesta ante tal diagnóstico consiste 
precisamente en la revalorización de la teoría cosmopolita hoy más realista que nunca en la era de las regresiones nacionalistas a escala universal (USA, UK, Europa y Rusia).

\section{Conclusión}

Es indudable que a partir de la década de los años ochenta del siglo pasado se han identificado y consolidado algunos BPM. La mayor parte de ellos están hoy incluidos en los ODS como objetivo de la CI. Pero, no obstante, el aumento cuantitativo de recursos (por ejemplo, la AOD a partir del Consenso de Monterrey 2002 ha superado los 140.000 millones de dólares anuales según el informe del CAD-OCDE, 2019), la CI es aún muy fragmentaria y poco sistémica. Sin embargo, los conceptos de desarrollo humano sostenible y de seguridad humana han generado un incremento cuantitativo y cualitativo de la interdependencia a través de un progresivo, aunque lento, cambio de paradigma de la soberanía nacional desde una perspectiva miope unilateral hacia una óptica de "soberanía inteligente" de suma positiva. La provisión de los BPM requiere una gobernanza sistémica que está en construcción. Aunque se haya avanzado en términos de gobernanza mundial, esta adolece de sistematicidad. Sufre de intermitencia, fragmentación y enfoque nacional o a lo sumo multinacional y aún no supranacional. La gobernanza solo ha llegado a un nivel internacional entendida como coordinación entre naciones horizontalmente y no de estas con el sistema y del sistema hacia ellas. Prevalece la visión reduccionista y no la estructural augurada por Waltz (1979). La gobernanza es inter-nacional (entre naciones) y no mundial. No obstante, se avanza en la percepción de MPM sistémicos que han generado un pacto global negativo (lo evitable) esperando transitar hacia un pacto mundial positivo (lo deseable y necesario). Se augura que la actual Agenda 2030 subsane este vacío en torno a una asunción universal de los diecisiete ODS encarnándolos como BPM que requieren urgentes PPM.

Parafraseando el segundo artículo definitivo de Kant para la paz perpetua; la augurada gobernanza mundial tal vez requiera una urgente Confederación de Federaciones regionales de Estados democráticos. En tal diseño, las Federaciones regionales ya existen (Oea, Ue, Lpa, Asean, Ua...). La mejor candidata a asumirse el rol de Confederación sería la Onu pero a condición de que se reforme democráticamente y que vuelva realidad el preámbulo de su Carta constitucional: nosotros, los pueblos de las Naciones Unidas, dando mayor reconocimiento a la sociedad civil mundial.

El constructivismo de Wendt incorporó a las teorías anteriores su variable social. Para él la paz, por ejemplo, es una construcción social pues no se posee por dotación natural. 
La nueva versión del cosmopolitismo (que trasciende a los globalistas) completa la fundamentación teórica propuesta, sobre todo, por Kaul Inge desde el institucionalismo de la ONU en términos de BPG.

La cadena de causalidades aquí propuesta es: si el objetivo final de la CI hoy es el de la realización efectiva del desarrollo humano sostenible para individuos y sociedades; si el desarrollo humano sostenible consiste en la ampliación de las posibilidades de opción de los individuos y los pueblos; si esta ampliación de libertades se logra solo en sistema democráticos incluyentes de la dimensión humana individual y colectiva; si la modalidad de democracia hasta ahora más incluyente y equitativa en términos de justicia es la del Estado social de derecho y este tipo de Estado se ha realizado en el mundo sólo por las socialdemocracias y no por la democracia liberal capitalista e individualista; se puede concluir que para que la cooperación internacional al desarrollo se convierta en una PPM proveedora de BPM (como los ODS, los Derechos humanos fundamentales, la lucha contra el cambio climático y contra el terrorismo, el deber de proteger, etc.), esta PPM debe ser emanada como outcome desde un sistema de socialdemocracia mundial (poliarquía cosmopolita) que adopte la forma de gobierno de un Estado de bienestar universal proveedor de BPM. El marco jurídico será un Convenio específico de cooperación internacional; su marco político será el multilateralismo multipolar; su marco teórico y ético es el cosmopolitismo kantiano y heldiano. Se trata de asumir como objetivo mundial la equidad cosmopolita en la época en la que el mismo sistema financiero imperante ha reconocido que el gran mal público mundial hoy es la insostenible inequidad universal.

El concepto de equidad universal contiene en sí un apelo a la idea de justicia mundial como lo hace la Ue (aún sin declararlo formalmente) en su cooperación con los Páises de África, Caribe y Pacífico (Acp) mediante la exención de aranceles comerciales a los productos Acp que entran al mercado Ue. Ello contiene un principio de justicia restitutiva de la Ue con sus excolonias ya desde el 1975 con el Tratado de Yaoundé, luego con los Convenios de Lomé $\mathrm{y}$, recientemente, con el Acuerdo de Cotonou.

Ahora bien, el marco ético de los distintos marcos de la CI aquí enunciados es, sobre todo, el tercer artículo definitivo de la obra la Paz perpetua de Kant: el derecho de ciudadanía mundial debe limitarse a las condiciones de una universal hospitalidad (Kant, 2012). En verdad, este tercer artículo definitivo, además de marco ético, funge de marco jurídico (Derecho internacional), político (justicia internacional), económico (conveniencia mundial). No es un caso que uno de los fenómenos recientes que más desafía a la CI es el de los flujos masivos de migrantes del Sur del mundo empobrecido hacia el Norte enriquecido, en gran parte, a expensas del Sur empobrecido. 


\section{Bibliografía:}

Aron, R. (1985), Paz y guerra entre las naciones, Madrid: Alianza.

Aron, R. (1951), Las guerras en cadena, Madrid: Alianza.

Agudelo, J. y Gustavo, R. (E). (2016), La cooperación internacional en transición: análisis global y experiencias para Colombia, 2015-2030, Cartagena: Editorial Bonaventuriana.

Agudelo, J. (E). (2013), Cooperar al desarrollo y desarrollar la cooperación: desafio post 2015, Cartagena: Editorial Bonaventuriana.

Agudelo, J., Miranda, P. y Toro, J. (2010), Evaluación del impacto de la cooperación internacional para el desarrollo en la gestión ambiental, Bogotá: Instituto de Estudios Ambientales (IDEA), Universidad Nacional.

Alonso, J. y Ocampo, J. (D). (2011), Cooperación para el desarrollo en tiempos de crisis, México: Fondo de Cultura Económica

Axelrod, R. (2006), The Evolution of Cooperation. Cambridge, USA: Basic Books

Axelrod, R. (1997), The Complexity of Cooperation: Agent-based Models of Competition and Collaboration, New Jersey: Princeton University Press.

Ayllón, B. (2013), La cooperación Sur-Sur y Triangular, Quito: Instituto de Altos Estudios Nacionales.

Barbé, E. (2011), Relaciones internacionales, Madrid: Técnos.

Bobbio, N. (1990), L'etá dei diritti, Torino: Einaudi.

Bobbio, N. (2008), El problema de la guerra y las vías de la paz, Barcelona: Gedisa Editorial.

Bull, H. (2005), La sociedad anárquica: un estudio sobre el orden en la política mundial, Madrid: Catarata.

Buzan, B. (1983), People, States and Fear: The National Security Problem in International Relations, Brigthon: Wheatsheaf.

Buzan, B. y Segal, G. (1998), El futuro que viene, Santiago de chile: Editorial Andrés Bello.

Cardoso, F. y Faletto, E. (1977), Dependencia y desarrollo en América Latina, Buenos Aires: Siglo XXI editores.

Dahl, R. (2009), La poliarquía. Participación y oposición, Madrid: Técnos.

Easton, D. (2006), Esquema para el análisis político, Buenos Aires: Amorrortu.

Easton, D. (2004), Enfoques sobre teoría politica, Buenos Aires: Amorrortu.

Easton, D. (1953). The Political System: An Inquiry Into the State of Political Science, New York: Knopf.

Escobar, A. (1996), La invención del tercer mundo: construcción y deconstrucción del desarrollo, Bogotá: Norma.

Ferroni, M. y Mody, A. (E). (2002), Bienes públicos internacionales: incentivos, medición y financiamiento, Bogotá: Alfaomega y Banco Mundial. 
Fukuyama, F. (2016), Los orígenes del orden político: desde la prehistoria hasta la Revolución Francesa, Barcelona: Ariel.

Habermas, J. (2009), Ay Europa!, Madrid: Trotta.

Held, D. (2012), Cosmopolitismo: ideales y realidades, Madrid: Alianza Editorial.

Held. D. y McGrew, A. (2003), Globalización, antiglobalización: sobre la reconstrucción del orden mundial, Barcelona: Paidós.

Held, D. (1997), La democracia y el orden global: del estado moderno al gobierno cosmopolita, Barcelona: Planeta.

Held, D. (2001), Modelos de democracia, Madrid: Alianza Editorial.

Hobbes, T. (2017), Leviatán, México D.F. Ed. Fondo de Cultura Económica

Hoffmann, S. (1987), Jano y minerva. Ensayos sobre la guerra y la paz, Buenos Aires: Grupo Editor Latinoamericano.

Kaldor, M. (2010), El poder y la fuerza: la seguridad de la población civil en un mundo global, Barcelona: Tusquets.

Kaldor, M. (2005), La sociedad civil global: una respuesta a la guerra, Barcelona: Tusquets.

Kant, I. (2020), Crítica de la razón práctica, Madrid: Verbum, S. I.

Kant, I. (2012), Sobre la paz perpetua, Madrid: Akal

Kant, I. (2003), Per la pace perpetua, Milano: Feltrinelli

Kaul, I., Grunberg, I. y Stern, M. (2000), Bienes públicos mundiales: la cooperación internacional en el siglo XXI, México: Oxford University Press.

Kaul, I. y Blondin, D. (2015), “Los bienes públicos globales y las Naciones Unidas” en: Ocampo. J. (E). Gobernanza global y desarrollo: nuevos desafios y prioridades de la cooperación internacional. Buenos Aires: Siglo Veintiuno Editores, pp. 71-114.

Kelsen, H. (2008), La paz por medio del derecho, Madrid: Trotta.

Keohane, R. (1989), Instituciones internacionales y poder estatal: ensayo sobre teorías de las relaciones internacionales, Buenos Aires: Grupo Editorial Latinoamericano.

Keohane, R. (1984), Después de la hegemonía: cooperación y discordia en la política económica mundial, Buenos Aires: Grupo Editor Latinoamericano. Keohane, R. y Nye, J. (1977), Poder e interdependencia: la politica mundial en transición, Buenos Aires: Grupo Editor Latinoamericano.

Keynes, J. (2013), Las consecuencias económicas de la paz, Barcelona: Planeta. Krasner, S. (1985), Conflicto estructural: El Tercer mundo contra el liberalismo global, Buenos Aires: Grupo Editor Latinoamericano.

Krasner, S. (1983), International Regimes, Massachussets: Massachussets Institut of Tecchnology.

Krugman, P. (2014), Acabad ya con esta crisis, Barcelona: Planeta. 
Krugman, P. (2010), La era de las expectativas limitadas, Barcelona: Ariel.

Luhmann, N. (2007), Teoría política en el estado de bienestar, Madrid: Alianza. Morgenthau, H. (1986), Politica entre las naciones: la lucha por el poder y la paz, Buenos Aires: Grupo Editorial Latinoamericano.

Ocampo, J. (E). (2015), Gobernanza global y desarrollo: nuevos desafíos y prioridades de la cooperación internacional, Buenos Aires: Siglo veintiuno Editores.

Ocampo, J. (E). (2006), Cooperación financiera regional, Santiago de Chile: CEPAL.

Ordoñez, G. (E). (2013), Manual de análisis y diseño de políticas públicas, Bogotá: Universidad Externado de Colombia.

Tassara, C. (2016), Cooperación internacional para el desarrollo: gobierno, economía y sociedad. Evolución de las politicas y escenarios futuros, Bogotá: Ediciones Unisalle.

Rawls, J. (1971), Teoría de la justicia, México: Fondo cultura económica.

Roth, A. (2005), Políticas públicas: formulación, implementación y evaluación, Bogotá: Aurora.

Rousseau, J. (2004), El contrato social, Zaragoza: Istmo.

Ruggie, J. (1975), "International Responses to Technology: Concepts and Trends", International Organization, Vol 29, No. 3, Wisconsin: University of Wisconsin Press.

Sanahuja, J. y Gómez, M. (Cs). (2001), La cooperación al desarrollo en un mundo en cambio. Perspectivas sobre nuevos ámbitos de intervención, Madrid: Cideal.

Sandel, M. (2013), Justicia: ¿hacemos lo que debemos?, Bogotá: Random House Mondadori.

Sen, A. (1981), Elección colectiva y bienestar social, Madrid: Alianza.

Sen, A. (2009), La idea de la justicia, Bogotá: Taurus.

Sotillo, J. (2011), El sistema de cooperación para el desarrollo: actores, formas y procesos, Madrid: Catarata e Instituto Universitario de Cooperación y Desarrollo.

Stigliz, J. (2016), La gran brecha: ¿qué hacer con las sociedades desiguales?, Bogotá: Taurus.

Stigliz, J. (2012), El precio de la desigualdad: el 1\% de la población tiene lo que el 99\% necesita, Buenos Aires: Taurus.

Wallerstein, I. (2005), El moderno sistema mundial, México: Siglo veintiuno Editores.

Waltz, K. (2001), Man, the State and War, New York: Columbian University Press.

Waltz, W. (1979), Teoría de la política internacional, Buenos Aires: Grupo Editorial Latinoamericano. 
Wendt, A. (2006), Social Theory of International politics, New York: Cambridge University Press.

Zolo, D. (2000), Cosmópolis. Perspectiva y riesgos de un gobierno mundial, Barcelona: Paidós.

\section{Documentos oficiales consultados}

Carta de las Naciones Unidas, (1945).

Declaración sobre derecho al desarrollo. Adoptada por la Asamblea General de las Naciones Unidas, (1986). Recuperado de https://www.ohchr.org/SP/ ProfessionalInterest/Pages/RightToDevelopment.aspx

Declaración de Rio de Janeiro sobre el Medio Ambiente y el Desarrollo, (1992). Recuperado de https://www.un.org/spanish/esa/sustdev/documents/ declaracionrio.htm

Informe Brundtland. Informe de la Comisión Mundial sobre el Medio Ambiente y el Desarrollo: Nuestro futuro común. (1987). Recuperado de http://www.ecominga.uqam.ca/PDF/BIBLIOGRAPHIE/GUIDE LECTURE_1/CMMAD-Informe-Comision-Brundtland-sobre-MedioAmbiente-Desarrollo.pdf

Informe sobre Los límites del desarrollo. Club de Roma y MIT Massachussets. (1972).

Declaración del Milenio, (2000). Recuperado de https://www.un.org/spanish/ milenio/ares552.pdf

Consenso de Monterrey sobre la Financiación sobre el Desarrollo, (2002). Recuperado de https://www.un.org/es/conf/ffd/2002/pdf/ACONF1983. pdf

Declaración de Roma sobre armonización de la cooperación, (2003). Recuperado de http://www.pazysolidaridad.ccoo.es/comunes/recursos/99891/ doc220765_Declaracion_de_Roma_sobre_la_Armonizacion.pdf

Declaración de Paris sobre la eficacia de la ayuda al desarrollo, (2005). Recuperado de https://www.oecd.org/dac/effectiveness/34580968.pdf Consenso europeo de desarrollo, (2006).

Programa de acción de Accra, (2008). Recuperado de https:/www.oecd.org/ dac/effectiveness/34580968.pdf

Los diez principios de Estambul sobre las Organizaciones de la sociedad civil para el desarrollo, (2010)

Declaración de Busan para la Cooperación Eficaz al Desarrollo, (2011). Recuperado de https://www.oecd.org/dac/effectiveness/49650200.pdf Declaración de Rio+20 sobre ambiente y desarrollo, (2012). 
Agenda de Acción de Addis Abeba de la Tercera Conferencia Internacional sobre la Financiación para el Desarrollo, (2015). Recuperado de https:// www.manosunidas.org/sites/default/files/docu_addis_abeba.pdf

Declaración de Paris sobre cambio climático, (2016).

Cooperación para el desarrollo. Informe sobre AOD, (2016). Paris: CAD, OCDE

The Economist Intelligence Unit. (2016), Democracy Index 2015: Democracy in Age of Anxiety, London: The Economist. Recuperado de https://www. yabiladi.com/img/content/EIU-Democracy-Index-2015.pdf 